\title{
Correlation of Overactive Bladder Symptoms and Falls With Injuries In Older People
}

\begin{abstract}
Background: The objective of this study was to evaluate the proportion of patients presenting with a fall also having a coexisting diagnosis of an overactive bladder $(\mathrm{OAB})$.

Methodology: This was a prospective case series study of patients over 65 years of age. Of a 137 patients presenting to the hospital during a 6-month period, 33 patients had a urinary tract infection and therefore 104 patients (average age: 79.3 years) were included for further analysis.

Results: In this cohort, $61 \%$ patients had a diagnosis of OAB. Only $1.9 \%$ of these had any investigations or treatment. The falls risk was multifactorial in 42 cases $(40 \%)$. A fracture was diagnosed in $73 \%$ of patients, $39 \%$ of which was a fracture neck of femur. The relative risk of sustaining a fracture and having OAB was 0.67 (95\% confidence interval, $0.42,1.05)$. A significant relationship was seen between a hip fracture and $\mathrm{OAB}$ diagnosis $(\mathrm{p}=0.0152)$
\end{abstract}

Conclusion: An overactive bladder is an important risk factor in patients presenting with falls. Falls in patients with an overactive bladder can have significant consequences such as a neck of femur fracture.

Keywords: fractures, falls, overactive bladder
Volume 3 Issue 6 - 2018

Onur Berber, Bijayendra Singh

Department of Trauma and Orthopaedics, Medway NHS

Foundation Trust, UK

Correspondence: Onur Berber, Department of Trauma and Orthopaedics, Medway NHS Foundation Trust, Windmill Road, Gillingham, Kent, ME75NY, UK, Email obarber@gmail.com

Received: August 13, 2017 | Published: November 16, 2018

\section{Introduction}

Reducing the risk of falls in older people is a multidisciplinary effort. National guidelines exist to improve care with respect to primary prevention and secondary care. Clearly, it is important to reduce falls risk as $40-60 \%$ of episodes lead to injuries with $5 \%$ being fractures, $1 \%$ of which result in a hip fracture. ${ }^{1-5}$ Recently, attention has focused on the condition known as an "overactive bladder" (OAB) as a previously under investigated but clearly important cause of falls in older people. It is specifically defined by the International Continence Society (ICS) as "urgency, with or without urge incontinence, usually with frequency and nocturia". ${ }^{6}$ The aim of our investigation was to assess the proportion of patients presenting with a fall, with or without a fracture that may have a diagnosis of an overactive bladder.

\section{Materials and methods}

This was a prospective study conducted in large district general hospital in the Southeast of England. The study was carried out over a 6-month period from August 2015 to January 2016. A specially designed data collection proforma was created. Patients were questioned as to whether previously investigated, diagnosed or on treatment for an overactive bladder. An attempt was made to scale the severity of the symptoms as can be seen on the proforma (Figure 1).

The study included patients over the age of 65 only. Patients with a concurrent microbiological diagnosis of a urinary tract infection were excluded to minimise confounding variables and symptoms of the latter could easily be confused for an overactive bladder.
Correlation of Over Active Bladder and Falls

\begin{tabular}{|l|l|l|l|}
\hline H.NO & DOB & Sex & \\
\hline DOA & DOD & LOS \\
\hline
\end{tabular}
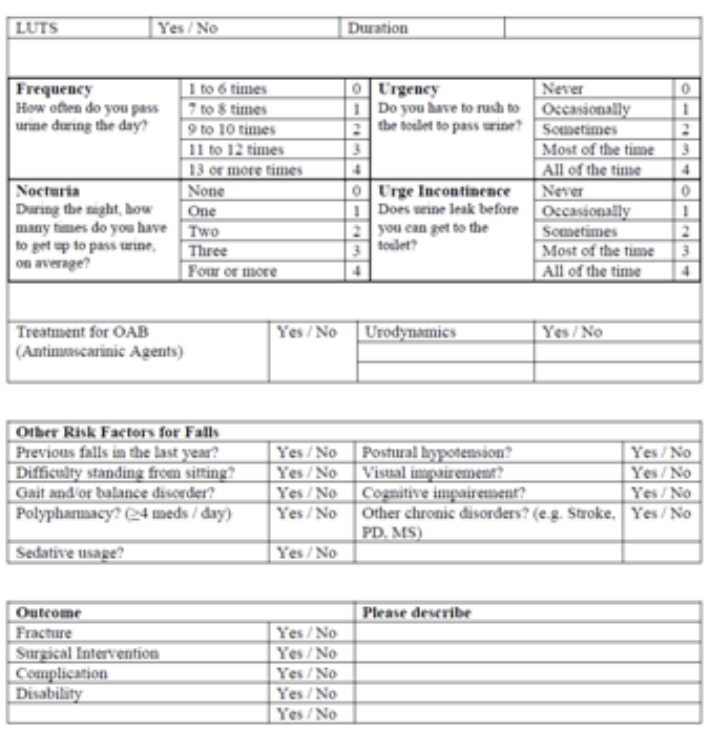

Key: LUTS: Lower minary tract symphoms: OAB: Oneractive blasder:

Figure I Data collection proforma designed specifically for this study incorporating standard falls risk and overactive bladder assessment. 


\section{Results}

During the period August 2015 till January 2016 a 137 patients were admitted secondary to a fall into hospital. Of these patients 33 had a positive urine culture for an infection and hence were excluded from the study leaving 104 patients for further analysis. The average age of the patient cohort was 79.3 years (range: 65-98 years). The male to female ratio was $1: 1.3$ (M:F-46:58). According to the International Continence Society definition, ${ }^{6} 63$ patients had a clear diagnosis of an overactive bladder (61\%). Only two of these patients had been previously diagnosed and were on treatment. Patients with an $\mathrm{OAB}$ diagnosis and those with milder symptoms constituted $89.4 \%$ of patients presenting within the study time period.

The general falls risk assessment indicated that $78 \%$ of patients had other factors contributing to the falls risk (Table 1) (Table 2). Of these patients $51 \%$ also had a concurrent diagnosis of an OAB. Otherwise, the most common risk factor was polypharmacy defined as a patient using $>3$ prescription medications a day (65\%) followed by visual impairment (32\%). The falls risk was multifactorial in 42 cases $(40 \%)$

Table I The incidence of other falls risk factors in the cohort of patients

\begin{tabular}{ll}
\hline Risk factor & $\begin{array}{l}\text { Number of patients } \\
\text { affected (\%) }\end{array}$ \\
\hline Polypharmacy (>3 medications / day) & $68(65 \%)$ \\
Visual impairment & $33(32 \%)$ \\
Gait / balance disorder & $10(9.6 \%)$ \\
Previous falls & $9(8.7 \%)$ \\
Difficulty standing from sitting position & $9(8.7 \%)$ \\
Chronic medical conditions & $5(4.8 \%)$ \\
Cognitive impairment & $3(2.9 \%)$ \\
Postural hypotension & $2(1.9 \%)$ \\
Sedative use & $\mathrm{I}(0.9 \%)$ \\
\hline
\end{tabular}

Table 2 This chart demonstrates the different fractures sustained in this group of patients. Percentages of the total fractures $(n=76)$ are given in brackets

\begin{tabular}{ll}
\hline Fracture type Hip & Incidence (\%) \\
\hline Intracapsular & $22(28.9 \%)$ \\
Extracapsular & $18(23.7 \%)$ \\
Pelvis & $8(10.5 \%)$ \\
Ankle & $6(7.9 \%)$ \\
Femur & $4(5.3 \%)$ \\
Humerus & $4(5.3 \%)$ \\
Spine & \\
Cervical & $1(1.3 \%)$ \\
Lumbar & $3(3.9 \%)$ \\
Tibia & \\
Plateau & $2(2.6 \%)$ \\
Shaft & $\mathrm{I}(1.3 \%)$ \\
Shoulder & $2(2.6 \%)$ \\
Hand (metacarpal) & $2(2.6 \%)$ \\
\hline
\end{tabular}

\begin{tabular}{ll} 
Table Continued.... & \\
\hline Fracture type Hip & Incidence (\%) \\
\hline Forearm & $2(2.6 \%)$ \\
Wrist & $\mathrm{I}(\mathrm{I} .3 \%)$ \\
Elbow (olecranon) & $\mathrm{I}(\mathrm{I} .3 \%)$ \\
Facial & $\mathrm{I}(\mathrm{I} .3 \%)$ \\
Rib & $\mathrm{I}(\mathrm{I} .3 \%)$
\end{tabular}

In this patient cohort of a 104 patients, 28 patients (27\%) presented with a fall only and not sustaining a bony injury. The other 76 patients (73\%) sustained a fracture of which included 41 hip fracture cases $(39 \%)$. Some patients presented with more than one fracture. Of the 41 patients with a fracture neck of femur, 22 had a qualifying diagnosis of $\mathrm{OAB}$. In the 35 patients with other fracture patterns, 7 were diagnosed with an $\mathrm{OAB}$. The relative risk of falling because of an $\mathrm{OAB}$ could not be calculated from the available data. However, the relative risk of sustaining a fracture from a fall and having an OAB diagnosis was 0.67 (95\% confidence interval, $0.42,1.05)$. The proportion of patients with a fracture neck of femur and having a diagnosis of $\mathrm{OAB}$ was $54 \%(\mathrm{p}=0.0152)$. Of the 41 patients presenting with a fracture neck of femur, 39 underwent surgical intervention in the form of a hemiarthroplasty or dynamic hip screw fixation. Of the remaining fracture patterns, 10 cases required surgical intervention.

\section{Discussion}

The impact of falls on healthcare providers around the world is substantial. The causes of falls are complex and multi-factorial. Falls prevention programmes are effective in preventing falls in older adults. ${ }^{7,8} \mathrm{~A}$ recommendation to assess for urinary incontinence is suggested in the National Institute for Clinical Excellence - Falls clinical guideline although may be underemphasized. ${ }^{9}$ With the prevalence of $\mathrm{OAB}$ quoted at $16.6 \%$ in a group of European countries ${ }^{10}$ and the reported relationship with urinary incontinence and falls ${ }^{11}$ suggests that this condition may be of greater clinical importance.

In this study of 104 patients all presenting with a fall to a large district general hospital, $61 \%$ of patients had a diagnosis of an $\mathrm{OAB}$ and only $1.9 \%$ were undergoing treatment for this. The remaining patients had not been questioned or investigated for the condition. This represents a common finding that patients are typically under diagnosed and undertreated for this condition. ${ }^{12,13}$ The risk of sustaining a fracture having a concurrent diagnosis of $\mathrm{OAB}$ was 0.67 (95\% Confidence interval $0.42,1.05$ ). This reflects the finding by Wagner et al. ${ }^{14}$ The proportion of patients with a fracture neck of femur and having a diagnosis of $\mathrm{OAB}$ was $54 \%$. This was a significant association $(p=0.0152)$. There have been no further studies investigating the risk of fracture and $\mathrm{OAB}$. The findings of this study is leading to change in local policy whereby the general falls assessment has been optimised to more effectively identify patients with a diagnosis of OAB. The ideal aim is earlier diagnosis in community setting to effect primary prevention. This is an ongoing local challenge.

The significant relationship between falls and fractures with $\mathrm{OAB}$ represents an important modifiable risk factor in patients both in primary and secondary prevention and also from an economical perspective. More effective screening and treating for $\mathrm{OAB}$ may represent a simple and effective method to reduce falls in the elderly.

\section{Acknowledgement}

None. 


\section{Conflict of Interest}

Authors declare that there are no conflicts of interest.

\section{References}

1. Campbell AJ, Reinken J, Allan BC, et al. Falls in old age: a study of frequency and related clinical factors. Age Ageing. 1981;10(4):264-270.

2. Tinetti ME, Speechley M, Ginter SF. Risk factors for falls among elderly persons living in the community. N Engl J Med. 1988;319(26):17011707.

3. Ryynänen OP, Kivelä SL, Honkanen R, et al. Incidence of falling injuries leading to medical treatment in the elderly. Public Health. 1991;105(5):373-386.

4. Lord SR, McLean D, Stathers G. Physiological factors associated with injurious falls in older people living in the community. Gerontology. 1992;38(6):338-346.
5. Nevitt MC, Cummings SR. Type of fall and risk of hip and wrist fractures: the study of osteoporotic fractures. The Study of Osteoporotic Fractures Research Group. J Am Geriatr Soc. 1993;41(11):1226-1234.

6. Wein AJ, Rovner ES. Definition and epidemiology of overactive bladder. Urology. 2002;60(5 Suppl 1):7-12.

7. Palvanen M, Kannus P, Piirtola M, et al. Effectiveness of the Chaos Falls Clinic in preventing falls and injuries of home-dwelling older adults: A randomised controlled trial. Injury. 2014;45(1):265-271.

8. Gillespie LD, Robertson MC, Gillespie WJ, et al. Interventions for preventing falls in older people living in the community. Cochrane Database Syst Rev. 2012;(2):CD007146.

9. National Institute for Health and Clinical Excellence. Falls: assessment and prevention of falls in older people (CG161). London: NICE; 2013. 